\title{
Pacemaker Implantation in Dextrocardia with Congenitally Corrected Transposition of the Great Arteries: A Case Report
}

\author{
Orçun Çiftci, ${ }^{\circledR}$ Ersin Doğanözü, ${ }^{\circledR}$ Kerem Can Yılmaz, ${ }^{\circledR}$ Mustafa Yılmaz, ${ }^{\circledR}$ illyas Atar, ${ }^{\circledR}$ Bülent Özin ${ }^{\circledR}$
}

Baskent Universitesi Tip Fakultesi - Cardiology Ankara, Ankara - Turkey

\section{Introduction}

Dextrocardia is a rare congenital cardiac malformation with an incidence of 0.83 per 10,000 births, characterized by displacement of the cardiac apex to the right of the thoracic midline. ${ }^{1,2}$ Congenitally corrected transposition of the great arteries (CCTGA) is a congenital malformation characterized by atrioventricular (AV) and ventriculoarterial discordance where patients are at increased risk of conduction system blocks and need for pacemaker (PM) implantation. ${ }^{3-5}$ PM implantation is a complex procedure in patients with situs inversus dextrocardia (SID) and CCTGA because of altered anatomy and operator inexperience. Herein we present a case of SID) and CCTGA who underwent a successful transvenous permanent PM implantation via left subclavian vein for permanent complete heart block.

\section{Case report}

A 13-year-old girl with SID, CCTGA, ventricular septal defect (VSD), subvalvular pulmonary stenosis (PS), atrial septal defect (ASD), right anterior aorta, and atypical ductus arteriosus had undergone a left Blalock-Taussig (BT) shunt between the left subclavian artery and the pulmonary artery at the age of 7 days, and Rastelli operation with ventricular septal defect closure, pulmonary stenosis relief, and epicardial PM implantation for postoperative permanent complete AV block at the age of 5 . At the age of 10, the pulse generator was exhausted. The patient was near

\section{Keywords}

Dextrocardia, congenitally corrected transposition of the great arteries, pacemaker implantation. predicted adult height and considered tall enough to be eligible for left ventricular endocardial pacing. No residual interventricular shunt was detected at the time of endocardial pacing system implantation, and so the risk of systemic embolism after the intervention could be discarded. Also, since the patient did not have sinus node disease, an atrial synchronous ventricular pacemaker (VDD mode) without atrial pacing lead was planned to be implanted. A PM pocket was opened in the left pectoral region due to the right-handedness of the patient. In anteroposterior (AP) fluoroscopic view, the left subclavian vein was cannulated and an endocardial passive PM lead with an atrial sensing ring was advanced through superior vena cava, morphological right atrium, and mitral valve to reach the apex of the non-systemic, morphological left ventricle (Figure 1A). The final position of the lead was confirmed in a right anterior oblique $40^{\circ}$ view. Sensing and pacing parameters were as follows: $R$ wave sensing amplitude of $20.2 \mathrm{mV}$; P wave sensing amplitude of $1.6 \mathrm{mV}$; ventricular pacing threshold of $0.3 \mathrm{~V}$ at a pulse width of $0.5 \mathrm{~ms}$. A VDD pulse generator was placed beneath the left prepectoral fascia. The pacing parameters were set as follows: basic and upper tracking rates of $60 \mathrm{bpm}$ and $130 \mathrm{~ms}$, respectively; sensed and paced AV delays of $120 \mathrm{~ms}$ and $150 \mathrm{~ms}$, respectively; ventricular pacing output of $5.0 \mathrm{~V}$ at a pulse width of $0.5 \mathrm{~ms}$; ventricular and atrial sensing thresholds of $2.8 \mathrm{mV}$ and $0.3 \mathrm{mV}$, respectively. After PM implantation, the patient did well with no postoperative complications, and normal functional capacity. Figure 1B depicts postimplantation ECG showing the right-sided precordial lead placement, PM in ventricular inhibited mode (VVI) due to a low atrial sensing $(0.4 \mathrm{mV})$. The problem was then corrected by increasing the atrial sensing to $0.18 \mathrm{mV}$ and tracking of sinus $\mathrm{p}$ waves was ensured. 

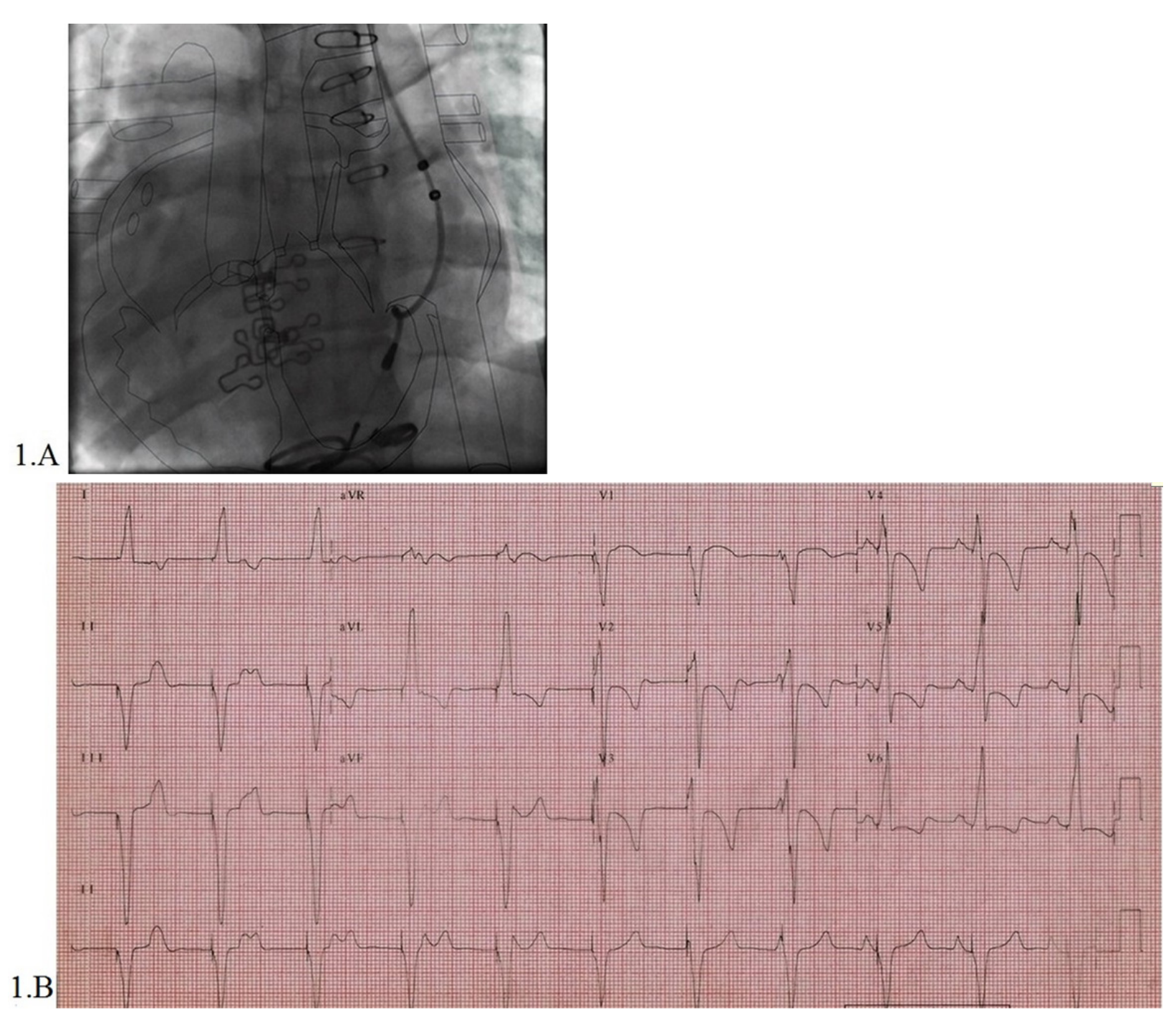

Figure 1 - 1A: Fluoroscopic view of the pacemaker leads mounted on a schematic representation of the anatomy of the heart. 1B: postimplantation ECG. $323 \times 265$ mm (72 × 72 DPI)

\section{Discussion}

Dextrocardia with situs inversus, also known as mirror-image dextrocardia, accounts for nearly $40 \%$ of all dextrocardia cases and is characterized by heart chambers located exactly opposite to their normal positions. ${ }^{1,2}$ CCTGA may co-occur in nearly $8 \%$ of dextrocardia with situs inversus. ${ }^{1}$ In CCTGA, the abnormal location of the AV node and the elongated His-Purkinje conduction system (His bundle $)^{3-5}$ increase the risk of complete heart block, both before and after corrective or palliative interventions, ${ }^{6,7}$ with an annual risk of $2 \% .{ }^{7}$ Daliento et al. ${ }^{8}$ followed patients with isolated CCTGA for 5 to 37 years and reported an incidence of $29 \%$ (5 out of 17 patients) of complete AV block, which was preceded by first- and second-degree AV block in two patients. Of note, one of these patients died, but it was not clear whether it was due to complete heart block. ${ }^{8}$ Surgical AV block after repair operations for CCTGA occurs at a rate of $3 \%$ and $16 \%$, with higher risk with arterial switch operation (12\%) than the Rastelli procedure. ${ }^{9}$ Anatomical factors possibly involved in the development of AV block include each of the AV node, the proximal or His bundle, or the more distal bundle branches. ${ }^{9}$ In situs inversus dextrocardia with CCTGA, the sinus node is located in 
the left-sided atrium, having a normal, but mirror-image, anatomical relationship with the terminal crest and superior vena caval entry into the left-sided atrium. In situs inversus CCTGA, the atrioventricular node is normally located at the apex of the Koch's triangle, and continues in the AV bundle. The bundle branches then end in the cord-like right bundle branch, and the fan-like left bundle branch, in the right and left side of the septum, respectively. ${ }^{9-11}$ PM implantation may be challenging in dextrocardia with CCTGA because of venous anomalies, ${ }^{12}$ altered cardiac position, and altered course of great vessels and cardiac veins. ${ }^{13}$ In dextrocardia with situs inversus and CCTGA, both right and left subclavian veins can be used for intravenous access; the ventricular lead is usually positioned in the apex of the non-systemic, morphological left ventricle, while the atrial lead, if used, is placed into the right atrial appendix. Since in dextrocardia with situs inversus the cardiac image is the mirror image of normal anatomy, the ventricular lead should be directed towards the spine in the right anterior oblique $40^{\circ}$ view and the cardiac apex in the left anterior oblique $30^{\circ}$ view during normal-oriented fluoroscopic imaging. It may also be useful to invert the fluoroscopic image from left to right to simulate normal anatomy. ${ }^{14}$ We had successful access to the left subclavian artery and no venous anomaly was observed. We then performed PM lead placement in anteroposterior view and confirmed the correct position of the lead using RAO $40^{\circ}$ view. We added the fluoroscopic static overlay of the PM lead to schematic drawing of cardiac anatomy to ease the understanding of lead localization.

\section{References}

1. Garg N, Agarwal BL, Modi N, Radhakrishnan S, Sinha N. Dextrocardia: an analysis of cardiac structures in 125 patients. Int J Cardiol. 2003;88(23):143-55.

2. Bohun CM, Potts JE, Casey BM, Sandor GG. A population-based study of cardiac malformations and outcomes associated with dextrocardia. Am J Cardiol. 2007;100(2):305-9.

3. Atallah J, Rutledge JM, Dyck JD. Transposition of the great arteries. In: Allen HD, Shaddy RE, Driscoll DJ, Feltes TF, eds. Moss and Adams' heart disease in infants, children, and adolescents: including the fetus and young adult. 7th ed. Philadelphia, PA: LWW; 2008. p.1147-60.

4. Warnes CA. Transposition of the great arteries. Circulation. 2006;114(24):2699-709.

5. Hornung TS, Calder L. Congenitally corrected transposition of the great arteries. Heart. 2010;96(14):1154-61.

6. Ly M, Belli E, Leobon B, Kortas C, Grollmüss OE, Piot D, et al. Results of the double switch operation for congenitally corrected transposition of the great arteries. Eur J Cardiothorac Surg. 2009;35(5):879-83.

7. Huhta JC, Maloney JD, Ritter DG, Ilstrup DM, Feldt RH. Complete atrioventricular block in patients with atrioventricular discordance. Circulation. 1983;67(6):1374-7.
In conclusion, implantation of permanent endocardial PM may be needed in patients with dextrocardia with situs inversus and CCTGA. Interventional cardiologists and electrophysiologists should be familiar with this condition. A good knowledge of cardiac anatomy may facilitate PM implantation in this population.

\section{Author contributions}

Conception and design of the research, Çiftci O. Acquisition of data: Atar İ, Özin MB. Analysis and interpretation of the data: Çiftci O, Doğanözü E, Yılmaz M, Yılmaz KC. Critical revision of the manuscript for intellectual content: Özin MB.

\section{Potential Conflict of Interest}

No potential conflict of interest relevant to this article was reported.

\section{Sources of Funding}

There were no external funding sources for this study.

\section{Study Association}

This study is not associated with any thesis or dissertation work.

\section{Ethics approval and consent to participate}

This article does not contain any studies with human participants or animals performed by any of the authors.

8. Daliento L, Corrado D, Buja G, John N, Nava A, Thiene G. Rhythm and conduction disturbances in isolated, congenitally corrected transposition of the great arteries. Am J Cardiol. 1986;58(3):314-8.

9. Baruteau AE, Abrams DJ, Ho SY, Thambo JB, McLeod CJ, Shah MJ. Cardiac conduction system in congenitally corrected transposition of the great arteries and its clinical relevance. J Am Heart Assoc. 2017;6(12):e007759.

10. Thiene G, Nava A, Rossi L. The conduction system in corrected transposition with situs inversus. Eur J Cardiol. 1977;6(1):57-70.

11. Wilkinson JL, Smith A, Lincoln C, Anderson RH. Conducting tissues in congenitally corrected transposition with situs inversus. Br Heart J. 1978;40(1):41-8.

12. Bottega NA, Kapa S, Edwards WD, Connolly HM, Munger TM, Warnes CA, et al. The cardiac veins in congenitally corrected transposition of the great arteries: delivery options for cardiac devices. Heart Rhythm. 2009;6(10):1450-6.

13. Fang $Y$, Jiang LC, Chen M. Successful pacemaker implantation in a patient with dextrocardia situs inversus totalis. Europace. 2009;11(11):1568-9.

14. Mond HG, Karpawich PP. Pacing options in the adult patient with congenital heart disease. New Jersey: John Wiley and Sons; 2008. 